Article

\title{
Looking for New Paths to Realize Cross-Sector Collaboration for Urban Regeneration: The Case of Castel del Giudice (Italy)
}

\author{
Luca Bartocci and Francesca Picciaia * (iD \\ Department of Economics, University of Perugia, 06135 Perugia, Italy; luca.bartocci@unipg.it \\ * Correspondence: francesca.picciaia@unipg.it
}

Received: 15 November 2019; Accepted: 27 December 2019; Published: 30 December 2019

check for updates

\begin{abstract}
New processes of urbanization have recently led to a concentration of inhabitants in big cities and a consequent depopulation of marginal areas. In Italy, this phenomenon has also affected mountain regions, which are still facing dramatic depopulation and economic depression. The incapacity of public administrations to remedy this public problem has recently led to the introduction of new forms of collaborations with actors belonging to diverse jurisdictional areas (governmental institutions, private companies, no-profit organizations, and local communities). These forms of partnership can be defined as cross sector collaborations and, in the case of community involvement, can also be arranged as community-based enterprises (CBEs). In this paper, we investigate the capacity of CBEs to be an effective instrument for cross-sector collaboration in the field of urban regeneration. In particular, by applying a specific analysis model inspired by the framework elaborated by Bryson, Crosby, and Stone (2015), we analyze an Italian experience of community engagement promoted in Castel Del Giudice, a small town in the Southern Apennines. Through document analysis and an interview method, the paper gives a twofold contribution to the field. Firstly, it provides a rigorous exploration of the preconditions, processes, structures, and results of a successful case of cross-sector collaboration. Secondly, it offers elements to assess potentiality and points of criticisms of CBEs to promote urban regeneration policies. In this sense, we conclude that the creation of a community-based network represents a second level of cross sector-collaboration that can potentiate the capacity to pursue the community interest.
\end{abstract}

Keywords: cross-sector collaboration; urban regeneration; community-based network; Italy

\section{Introduction}

Urban regeneration has become a relevant topic not only in disciplines that focus more on the transformation of a territory (i.e., urban planning, environmental management, and geography) but also in other branches of study less directly involved in this issue (i.e., sociology, economics, political sciences, and public management). Globalization has produced a new process of urbanization, with a concentration of inhabitants in big cities and depopulation of marginal areas [1]. Even Western countries are affected by this phenomenon; especially, some rural areas are facing the challenge of offering a high-level life standard to their residents in the attempt to fight depopulation and marginalization [2]. Moreover, the last economic crisis has reduced the share of public expenditure that can be allocated for these issues [3].

In such a scenario, the involvement of civil society is seen as an avenue for elaborating new solutions and multiplying expertise and financial resources [4]. In this sense, some social innovations are inspired by the idea of engaging the community to cope with public problems. The idea of a community-based enterprise (CBE) has been developed, tested, and put into practice. A CBE can be 
defined as 'the result of a process in which the community acts entrepreneurially to create and operate a new enterprise' to pursue the common good [5]. Empirical cases of CBE have been recognized first in some less-developed regions of the world [5,6], but a similar idea has also been implemented in Western countries. This trend has affected Italy, where an increasing number of CBEs, especially in the form of cooperatives, have been established in recent years [7].

In this paper, we investigate the capacity of CBEs to be a convenient instrument for cross-sector collaboration in the field of urban regeneration. Following Evans and Shaw [8], we define urban regeneration as a set of policies and actions to transform a place (residential or industrial, or a natural site) affected by a condition of environmental, social, and/or economic decline. The distinctive feature consists of the fact that sustainable and long-term improvements for the life conditions of a local community are the ultimate goal of the initiatives. More precisely, in this work, we assume that CBEs can be considered as experiences of cross-sector collaboration in which different actors, belonging to different jurisdictional areas (i.e., public and private sectors), interact and collaborate to cope with problems qualifiable as public [9]. We are aware that the concept of cross-sector collaboration presents strong analogies and bonds with those of public governance and co-production. Especially, it rather overlaps the idea of co-management that has already been used in studies on environmental and urban management [10].

In this study, a specific analysis model of cross-sector collaboration, which is inspired by the framework elaborated by Bryson, Corby, and Stone [11], is applied to investigate an Italian experience of community engagement promoted in Castel Del Giudice. This case refers to a small village in Southern Italy, which has been struggling with the problems of depopulation and economic depression. Current literature [12] has already underlined that community engagement and group strategies can be better investigated in small communities. Our single-case research is based on a document analysis [13] and the interview method [14,15]. In particular, we examined companies' official documents such as constitutive acts, statutes, certificates of incorporations, and financial statements. Moreover, a two-round interview with the mayor of the town was carried out. The first interview, of about one hour, was based on a semi-structured questionnaire. In the second, which lasted about $45 \mathrm{~min}$, a revision and validation process of data and pieces of information was conducted, along with the collection of integrative data. The focus on the mayor is mainly due to his active role in the Castel del Giudice political arena. He can be considered the main actor in the political life of the town for the last two decades, playing a crucial role in promoting the network we analyze.

The study gives a two-fold contribution to the field. Firstly, it provides a rigorous exploration of preconditions, processes, structures, and results of a successful case of cross-sector collaboration. Secondly, it offers elements to assess the potentiality and weaknesses of CBEs to promote urban regeneration policies. In this perspective, our main conclusion is that CBEs tend to form a kind of network that, if it is consistently governed, allows the community to pursue more effectively its own interest. In fact, previous studies on cross-sector collaboration in urban regeneration are based on the analysis of specific programs that has implied collaboration between a limited number of actors (in general, a public agency with a non-profit organization). On the contrary, in our study we propose an exploration of new forms of collaboration among a broader set of actors that belong to different sectors and create a network of new institutional units. Particularly, the main evidence of this experience is that the presence of formal and informal links among all the initiatives can make the program more effective.

The article is structured as follows. In Section 2, the theoretical background and the analysis framework are illustrated, organizing the content in two different sub-sections. In Section 3, the framework is presented then, in Section 4, the analysis of the empirical case is described. Section 5 is devoted to the discussion of results. The study concludes with Section 6, that contains conclusions and some final remarks.

\section{Theoretical Background and Analysis Framework}

Since the paper is based on the idea that the creation of a network of public and private actors represents a feasible and promising way to effectively cope with the problem of urban regeneration, 
we have connected it to the literature on cross-sector collaboration. However, we are aware that this concept presents strong analogies and links with the concepts of public governance, co-production, and especially co-management. In this sense, a short review of significant literature on the connections among these themes is reported in the following sub-section. In a separate sub-section the notion of CBE is examined as we interpret our study case as a community interest network of different institutional units. Finally, the third sub-section is devoted to the analysis framework we apply in the empirical part.

\subsection{Cross-Sector Collaboration in Urban Regeneration}

In the last two decades, cross-sector collaboration has become a relevant stream of research in the field of public management. In their seminal study, Bryson, Corby, and Stone [9] define cross-sector collaboration as 'partnerships involving governments, business, nonprofits and philanthropies, communities, and/or the public as a whole'. It is a very broad perspective based on the idea that interaction among different actors, belonging to different domains, can be an effective key to understand how organizations work to cope with public problems, especially with issues that are considered more socially challenging [16].

Different drivers to promote cross-sector collaboration have been supposed and recognized. Firstly, we are living in shared-power world where different types of actors feel involved and entitled to act in facing global problems [16]. Moreover, some of these actors, especially those that belong to the government sector, are often accused of being ineffective when they act on their own and some kind of power sharing is advocated [17]. In this sense, attempts at collaboration with private companies, non-profit organizations, groups of interest and even lay citizens should be promoted by public administrations to deal with their problems in terms of trust and legitimacy [18]. More in general, it is believed that at the basis of every form of collaboration lies the actors' awareness of their incapacity to deal with challenging problems on their own [19].

The idea that collaboration among entities, organizations, and, more generally, actors from different sectors can produce positive effects on the capacity to deal with public problems has been also emphasized in the multifaceted concept of public governance. Though there exist various versions and labels of this concept (i.e., new public governance, network governance, shared governance, and democratic governance), the general view is that the engagement of actors belonging to different jurisdictional areas in a common partnership is a tool to renew government and to repair the public sector damaged by the harmful effects of the New Public Management (NPM). In particular, some [20,21] believe that the spread of a market-inspired vision has pushed towards a fragmentation of the public sector and an accentuation of competition, with an exacerbation of the conflict between individual and public interest. Subsequently, the NPM has had the effect of favoring the erosion of traditional social values (i.e., legitimacy, representativeness, participation, and equity) that should connote public action, and of deteriorating the "public ethos" [22]. Finally, it has produced a disaggregation and indefiniteness in public realm boundaries, also increasing the opacity of public action and the passivity of citizens [23].

In truth, the view that society may benefit from the interaction between public and private subjects is also at the basis of economic studies on co-production. In brief, we can define it as a process to get the provision of a public service with the contribution of public and private subjects [24]. However, this concept has been interpreted in different ways and there are now several taxonomies that have been developed from it [25]. Specifically, based on the different level of activity shared by the actors, it is possible to distinguish between co-production in the stricter sense, co-management and co-governance [26]. Especially, the concept of co-management has known significant application in the field of environmental and urban management. It is generally considered as the result, rather than the starting point, of a process in which the power is shared among public and private actors [10]. The general idea is that an institutional entity with jurisdiction over an area develops some kinds of partnership among different stakeholders to share the 'management functions, entitlements, 
and responsibilities for a given territory, area, or set of natural resources' [27]. In the field of environmental management, some positive effects of co-management have been highlighted [10]: better allocation of tasks among actors involved in the partnership, easiness of exchanging resources among them, reduction of transaction costs, power and risk sharing, and better conflicts resolution. Moreover, the effectiveness of co-management in respect of commissioning in public service management has been emphasized [28], even though some failing cases of co-management are reported in the literature [29,30].

\subsection{CBEs as Tools of Cross-Sector Collaboration}

In this study, we considered CBEs as organizations in which a convenient collaboration among different actors can be promoted. A first notion of CBE in the field of studies on management is given by Peredo and Chrisman [5]. They consider the following elements as essential parts of that notion: (1) existence of an aggregation of people motivated by a social goal, rather than an economic one; (2) a large majority of them must have a certain level of commitment to the enterprise; and (3) participative mechanisms must be designed. In brief, a CBE should be 'owned, managed, and governed by the people' [5].

Beyond this theoretical perspective, impulses to spread cases of CBE have been aided by legal reforms in some Western countries. In particular, in the UK, under the push of the New Labor wave, the setting of specific organizations able to engage public and private actors to pursue social goals and develop projects for regenerating local communities has been promoted [31]. To this aim, the figures of the community-interest company (CIC) and of the community-benefit society were introduced. A significant number of CICs have been especially involved in urban regeneration projects. From a legal point of view, they are entities that have the form of limited companies and comply with the community interest test (i.e., a reasonable person might consider that a CIC carries on its activities for the benefit of the community or a section of it) and the asset lock requirement (i.e., respect the prohibition of non-division of the capital).

A similar approach has been followed in other European countries, such as Spain where the Sociedad Limitada de Interés General has been regulated since 2011 [32]. In some other countries, the choice has been to give special value to cooperatives with their combination of entrepreneurship and sociality. In France, a specific law, the Société Coopérative d'Intérêt Collectif, was passed in 2001 [33]. Even the EU Commission elaborated some guidelines to promote the spread of social enterprises intended as institutions 'whose main objective is to have a social impact rather than make a profit for their owners or shareholders' [34]. In general, we can affirm that the legal approach followed by the European countries has been less restrictive than the view conceptualized in the literature where a clear reference to the community must be recognized at the origin of a $\mathrm{CBE}$, in designing its governance system, and managing its activity. In other words, for some theorists [5] a CBE is intended as the result of a corporative action, while many legal systems are more focused on the social aim of the company and the fact that effects of its activity will be felt in the local community.

This second approach is acknowledgeable also in Italy, where the establishment of social enterprises has been followed by the new phenomena of community cooperation and of CBE. This recent trend involves cooperatives and limited companies that operate in traditional legal forms but, in reality, they also include elements of reference to a local community. This community-oriented interest should express the "true reason" of this kind of organization and it is ultimately related to the attempt to contribute to the economic, social and environmental development of a marginal area [7,35]. A participatory approach to involve residents in the governance and management systems of these organizations is also expected, and reinvestment of profits for the local community is recommended in the literature [35]. Currently, there is no official census of Italian CBEs but some cases are recognized in empirical studies $[7,36]$. Generally, these enterprises consist of small organizations, which operate in small areas. They are the result of projects in which collaboration between local residents and public authorities is realized in order to promote renovation or regeneration of public assets, buildings, and spaces in an urban or rural context [3]. 


\section{The Theoretical Framework}

In this study, we applied an adaption of the framework proposed by Bryson, Corby, and Stone [11]. This conceptual scheme represents an updated version of a model that had been previously drafted by the authors [9] and successively revised in the light of the most recent literature on cross-sector collaboration. The result is a kind of framework of the frameworks that provides a complete (though complex) scheme to investigate empirical cases. To make this scheme more convenient for the scope of our analysis, we focused only on some elements. Moreover, the items we considered relevant were grouped in three main categories: preconditions, cross-sector collaboration in action, and results. In this way, we obtained the following model of analysis (Table 1).

Table 1. Theoretical framework.

\begin{tabular}{cc}
\hline Categories & Items \\
\hline Preconditions & Public sector failure \\
& $\begin{array}{c}\text { Institutional environment opportunities } \\
\text { Legitimacy, leadership and additional contribution of actors } \\
\text { Pre-existing relationships among actors }\end{array}$ \\
Cross-sector collaboration in action & Formalized structures \\
& Formal and informal processes \\
& Collaborative capacity and competencies \\
Leadership \\
Governance
\end{tabular}

Source: Authors' elaboration from Bryson, Corby, and Stone (2015).

Preconditions refer to general antecedents or initial conditions of cross-sector collaboration. Usually, the starting point is the fact that government recognizes its incapacity to remedy a public problem by itself or, at least, sees in the partnership approach a possibility to better cope with that problem [19]. How a plan to promote collaboration can emerge and its feasibility are influenced by the actors' specific institutional environment. In some cases, norms and policies can require the involvement of private actors in designing or managing public services or activities. In others, this involvement can be the result of a voluntary process, possibly based on the exploitation of contingent windows of opportunities [37]. In this scenario, a relevant role can be also played by supra-ordinate institutions (such as regions, the central state, supra-national bodies, and international institutions). In this sense, a significant situation can be represented by the possibility to meet requirements to benefit from specific public funds [38]. Systems of cultural beliefs and political preferences can also affect the potentiality to promote experiences of collaboration among public and private subjects. Furthermore, we could recognize other preconditions, such as a high level of legitimacy of actors to act, their leadership, and the additional contribution they can offer in terms of expertise, relationships, technology, and financial resources [39]. Generally, we could presume that the existence of relationships among actors of different jurisdictional areas plays a relevant role in creating possibilities of partnership among actors [40].

A second category of items examines a further stage: cross-sector collaboration in action. Based on Bryson, Corby, and Stone's framework [11], this expression denotes processes, structures, and links among them, through which factual experiences of co-management are conducted. Clearly, it is possible that 'the research on process overlaps with some aspects of the research on initial conditions and structures' [9]. Processes are focused on activities and communication while structures are more about organization or "organizing" [41]. Both of them should be thought of, designed and operationalized in a way to pursue trust, commitment and legitimacy [42,43]. In the intersection between processes and structures we could identify other variables that are able to affect the functioning of a collaboration, 
i.e., collaborative capacity and competencies of the other actors, the role and skills of leaders, and the governance system.

Finally, a third level of analysis was proposed with regard to the results of cross-sector collaboration. Direct and indirect effects must be considered. In terms of time and effectiveness, immediate outputs but also intermediate and long-term outcomes can be identified [44]. As far as their domain concerns, they refer to the economic, social, and environmental dimensions. However, outcomes must be interpreted in a public-value-oriented perspective. The concept of public value is interpreted in different ways in the literature [45]. Here, we interpreted it in connection with the idea of the public sphere [46]. More specifically, a creation of public value can be recognized when there is an enhancement of a 'a democratic space' that entails 'values, places, organizations, rules, knowledge, and other cultural resources held in common by people through their everyday commitments and behaviors, and held in trust by government and public institutions'. It is 'what provides a society with some sense of belonging, meaning, purpose and continuity, and which enables people to thrive and strive amid uncertainty' [46]. Following the pattern of Bryson, Corby, and Stone [11], we include accountability processes in this category of items, even though these processes are also connected to the various activities and phases of collaboration. Accountability entails both formal and informal mechanisms and standards.

\section{The Experience of Urban Regeneration of Castel del Giudice (Italy)}

Castel del Giudice is a very small municipality in the centre of the Italian Apennines. It belongs to the Region of Molise, close to the border with Abruzzo. It seems that its name derives from the castle (castello) of an ancient noble family (del Giudice) that does not exist today. At the end of 2018, the entire population was 312 inhabitants [47] and was in constant decline. Historically, the population of Castel del Giudice has always been linked to agriculture and pastoralism. In particular, the town was a resting place of transhumance [48] and has not been involved in any industrial development, and has suffered from a strong depopulation process in the last decades. Unfortunately, all written documents on the history of the town were definitively destroyed during Second World War (WWII), when German soldiers, barricaded throughout the Gustav Line, set the entire town on fire on 8 November 1943 [48].

We could consider the case of Castel del Giudice very similar to almost all Italian mountain areas. After WWII, these areas were involved in a depopulation process related to their social, economic and structural marginality in comparison with urban centers. In addition, recent changes in farming and pastoralism had made these activities no longer profitable [49], forcing entire populations to abandon their main economic activities. The consequence is the presence of deserted areas and abandoned villages, with some large-scale implications: 'the depopulation of isolated villages is not only a problem for the local community. In fact, the general abandonment of these territories means a lack of upstream maintenance and, therefore, a possible transfer of hydro-geological problems downstream to plain areas' ([12], our translation). Today, in the Italian territory, there are 8092 municipalities, where almost half (44\%) have less than 2000 inhabitants. Focusing on the 2596 mountain municipalities, the situation becomes even more dramatic: $93 \%$ of these municipalities host less than 5000 inhabitants, though they cover about four fifths of the entire Italian territory, and $68 \%$ of the municipalities have less than 2000 inhabitants but occupy $60 \%$ of the mountain areas [50]. This implies many problems in terms of abandoned territories and economic depression of marginal areas, to the point that, recently, a legislative intervention (law n. 158/2017) has been approved, containing measures for the financial support of small municipalities. Particularly, this intervention has the aim to counteract depopulation, the lack of public services provision and the isolation of these areas.

In the case of Castel del Giudice, a strong action against its slow but inexorable depopulation was started at the end of the 1990s based on the initiative of the local government led by the mayor Lino Gentile. He was born in this town and he was elected as mayor for the first time in the period from 1999 to 2009 for two consecutive terms and, being re-elected in 2014 is still in charge. In 1999, trying to start a process of urban regeneration, the local government decided to restructure the buildings of the elementary school, previously closed for the lack of students, and to make the use of these buildings 
more productive and suitable to the needs of the community. The establishment of a company was promoted by the municipality to meet these needs. The local population was involved in the decision through public meetings, and an "affective entrepreneur" joined the company. It is the mayor himself who offers a definition of this peculiar figure, defined as 'an entrepreneur who had gone to make his fortune out of our territory and came back to offer a contribution to his place of origin. In all our initiatives the entrepreneurial component is central, as it offers not only financial but also technical supports, which is the ability to run a business', (Interview with Lino Gentile, mayor of Castel del Giudice-our translation). In other words, 'effective entrepreneurs' are business owners who decided to invest in their native territory: their intervention is related to new ventures, not necessarily tied to their original business. These latter, in fact, remain as autonomous businesses, often far from their investments in Castel del Giudice. The concept of 'affective entrepreneurs' could be similar to another recent Italian phenomenon, mostly studied by anthropological literature: the ritornanti, namely young entrepreneurs who decided to come back to their territory of origin to create new ventures, especially innovative ones.

The limited liability company, called R.S.A. San Nicola s.r.l., began its activity in 2002. Its main business is related to residential care activities and facilities for elderly people. Now, it employs 25 workers and its last available results are $€ 616,000$ as total revenue and $€ 134,525$ as equity (data from Orbis, 2017, accessed 30th September 2019). The Municipality of Castel del Giudice still owns a little share $(3.58 \%)$ of the equity, while the affective entrepreneur ( $\mathrm{D}^{\prime}$ Andrea s.p.a., a joint stock company specializing in metal products and founded by a former resident of the area) is the major shareholder (with $78.19 \%$ of the equity). It has to be noted that the remaining part of the capital is owned by another 23 members, with a personal share between $0.21 \%$ and $0.96 \%$. They are all inhabitants of Castel del Giudice or residents of neighboring municipalities. From the success of the activity stemmed other initiatives, e.g., a pharmacy and a supermarket, which had been closed for years, was reopened. In other words, the presence of the employees of the R.S.A. S. Nicola, the users and their relatives, give a little but significant stimulus to the local economy.

Furthermore, this was the input for elaborating other community-oriented initiatives, especially the establishment of other two ventures: Vello s.p.a., which owns and manages Hotel Borgotufi, and Melise s.r.l., an agricultural enterprise specializing in apple cultivation. Borgotufi is an albergo diffuso, that is to say a multi-building hotel spread throughout the town center in different buildings. At the beginning of 2002, just after the creation of R.S.A. San Nicola s.r.l., the inhabitants of Castel del Giudice were summoned by the local government to discuss the idea of transforming the abandoned buildings into a multi-building hotel. About $80 \%$ of the owners of the stables offered their availability to participate in this project '[and] this was surprising, also because-for the first time-the old inhabitants of Castel del Giudice looked forward to the future of the community and not nostalgically back to their past' (Interview with Lino Gentile, mayor of Castel del Giudice-our translation). At this point, the municipality assessed the suitability of buildings with the aim of the activity and created a company, named Vello s.p.a., with two private entrepreneurs. These latter represented the "managerial side" of the company, founded in 2003. In 15 years, $€ 7 \mathrm{~m}$ has been invested in the properties. These funds were covered by some EU grants and by revenues deriving from the sale of non-strategic buildings owned by the Municipality itself. In 2015, the hotel began its activity with 25 different apartments and rooms. Vello s.p.a. owns and manages the Hotel Borgotufi and has 13 employees. Its last available results are $€ 230,000$ as operating revenue and $€ 100,000$ as equity (data from Orbis, 2017, accessed 30th September 2019). The members of this company are Castel del Giudice Municipality with a share of $20 \%$, and two companies: D'Andrea s.p.a. and Ricci s.r.l., both with a share of $40 \%$. Ricci s.r.l. is a company specializing in the construction of residential and non-residential buildings, with its headquarters in Castel di Sangro (a town $17 \mathrm{~km}$ far from Castel del Giudice).

Melise s.r.l. (a limited liability company) is another "piece" of this experience. Starting from an initial idea concerning the re-use of abandoned land properties, the company, established in 2003, now grows 40 hectares of organic apples. The production is directly sold in local markets, while the 
non-marketable part is usually sold to an Italian company specializing in the production of organic fruit juices. Its activity is also expanding through new types of crops. Two years ago, the company started cultivating organic barley and hops for the production of craft beer. What is interesting is that 'the thrust of every initiative is to turn weaknesses into strengths. All abandoned land properties, initially considered as marginal assets, become opportunities especially for quality productions' (Interview with Lino Gentile, mayor of Castel del Giudice-our translation). This company is also tied to the "albergo diffuso" Hotel Borgotufi since there is a service contract, for which Melise s.r.l. deals with the management of urban furniture and green areas related to accommodation services. Its last available results are about $€ 79,000$ as operating revenues and $€ 750,000$ as equity, and it employs three workers. It is noteworthy that, from a membership point of view, Melise s.r.l. is owned by more than 50 inhabitants of Castel del Giudice and neighboring areas. Among the stakeholders, there is again D'Andrea s.p.a with a share of $52.67 \%$. The Municipality of Castel del Giudice is present as a shareholder with a share of $1.2 \%$. It is interesting that in this case, albeit in a marginal percentage, there are other two adjoining Municipalities-Capracotta, with a share of $0.26 \%$, and Sant'Angelo del Pesco, with a share of $0.13 \%$ (data from 2017, from CCIAA Molise).

The last and most recent experience is Artemisia Società Cooperativa Agricola di Comunità, an agricultural community-based cooperative. Actually, this cooperative, created in 2017, has not yet completely started its activity, since is still waiting for some EU grants. Its main fields of business are cultivation and collection of wild herbs and beekeeping. This latter, in particular, is a result of a wider project that has involved both the Municipality of Castel del Giudice and its inhabitants. The municipality has organized a training course on beekeeping and has purchased beehives for the treatment of bees and the production of honey. The participants of the training course will each be responsible for one beehive. The beehives will be located in different parts of the area around Castel del Giudice and will constitute a sort of "widespread apiary". The entire production of honey will be sold under the label Artemisia. It is also worth noting that the municipality had a central role in financing the activity. As described by the mayor, 'the Municipality has invested $€ 100,000$, of which $€ 60,000$ comes from the region with a public grant for agriculture. It was able to contribute $€ 20,000$ because it received a sum of money as a resolution of an old dispute with the water services provider. Half of this funding was diverted to Artemisia. The idea was to not directly contribute to the cooperative but to offer people the possibility to do so. In this sense a bonus of $€ 5000$ has been proposed to any Artemisia's cooperative member who had no independent capacity to finance his investment, so as to partially support his contribution' (Interview with Lino Gentile, mayor of Castel del Giudice-our translation). Currently, Artemisia Società Cooperativa Agricola di Comunità has five members. All them are young inhabitants of Castel del Giudice (they are under 35 years old), who work for the cooperative itself. The aim of the cooperative is to offer a stable job so to allow individuals to choose Castel del Giudice as their home, since 'it is better to have a job in Castel del Giudice, instead of being unemployed in Turin', (Interview with Lino Gentile, Mayor of Castel del Giudice—our translation).

The whole experience of Castel del Giudice can be interpreted as the progressive creation of a network that connects the above-mentioned four ventures and, in this sense, a map of interconnections among the Municipality of Castel del Giudice, the neighboring municipalities, the private enterprises involved, and the community can be presented (Figure 1). 


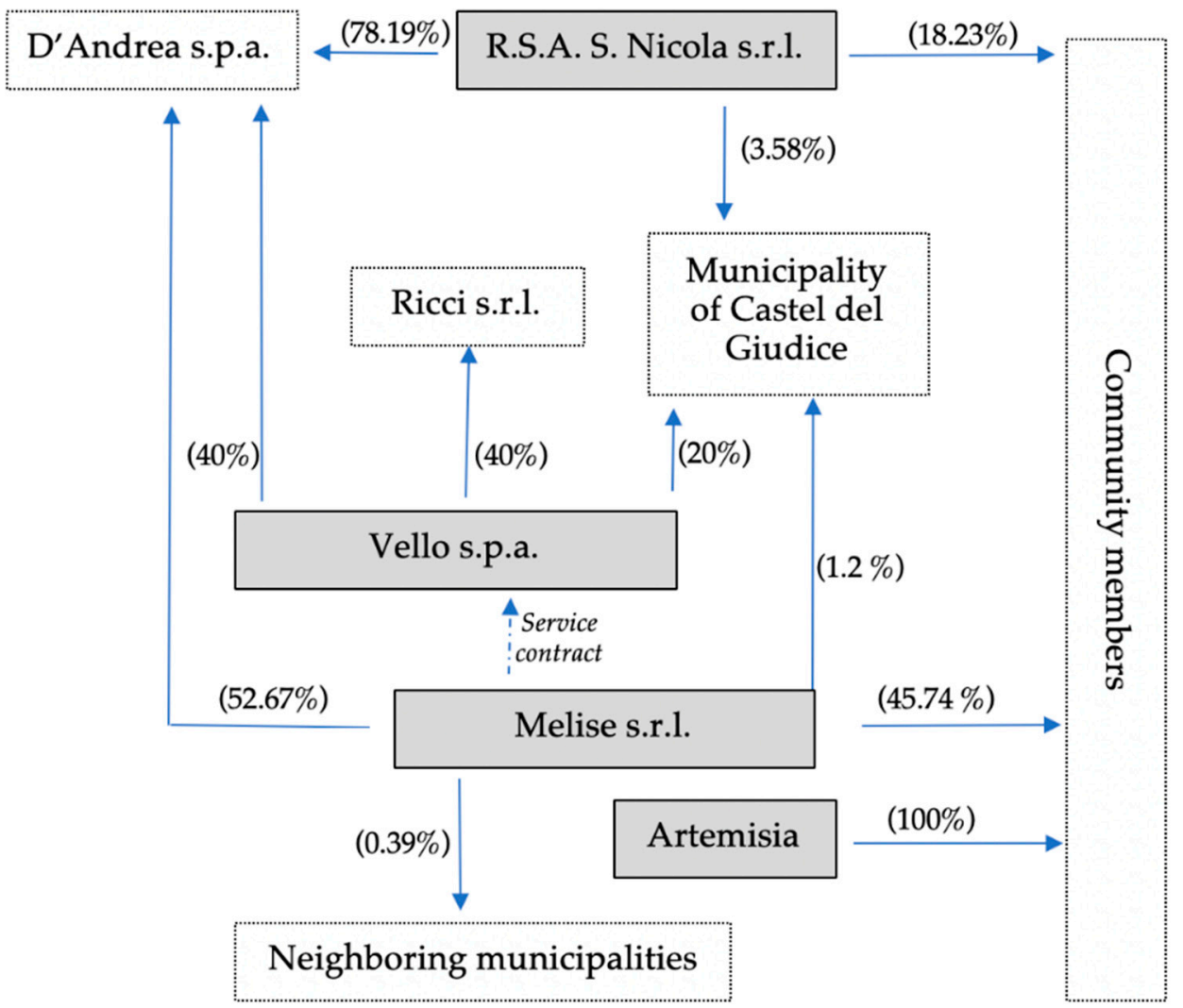

Figure 1. Castel del Giudice network. Source: Authors' elaboration.

These interconnections are firstly based on a complex system of shareholdings (in brackets the percentage of shares). At the same time, this network represents the experience of cross-sector collaboration among public institutions, private enterprises, and community members.

\section{Discussion}

The case of Castel del Giudice evidences the presence of diverse initiatives created in a few years in order to resolve social and economic problems and to structure an urban regeneration process. These initiatives, i.e., RSA S. Nicola s.r.l., Vello s.p.a., Melise s.r.l., and Artemisia Società Cooperativa Agricola di Comunità, can be considered as places where an experience of cross-sector collaboration among different actors has been promoted and organized. These actors are both public (the Municipality of Castel del Giudice) and private (two companies corresponding to two entrepreneurs). Furthermore, we identified also the community as an actor since inhabitants of the region have been involved in some public decisions and some of them have been even engaged as members and/or employees of the organizations above. In this sense, it is possible to consider each one of these organizations as a system of interrelationships, which implies the sharing of knowledge, functions, entitlements, and responsibilities that can be investigated in the light of a cross-sector collaboration approach [11]. Moreover, in the case of Castel del Giudice, we could acknowledge a second level of collaboration among the actors by interpreting the new four companies that were established as units of the same network promoted and coordinated by the Municipality to pursue effects in terms of urban regeneration. In other words, the formal and informal relationships that exist among them allow the four companies to be considered as a single network that also includes the municipality and that is inspired by the interest of the community. Specifically, based on the theoretical framework presented in Section 3, we wanted to discuss what we call an experience of community-based networking as a significant case of cross-sector collaboration. As such, inspired by Bryson et al. [11], we used three different categories of items of analysis: preconditions, that is to say the elements that allowed and favored the start of 
the experience of cross-sector collaboration; cross-sector collaboration in action, namely how it has been designed, organized and implemented; and results, i.e., the general outcomes of collaboration, in terms of public value creation and accountability processes (Table 2).

Table 2. Cross-sector collaboration in the community-based network of Castel del Giudice.

\begin{tabular}{|c|c|c|}
\hline Categories & Items & Castel del Giudice \\
\hline \multirow{4}{*}{ Preconditions } & Public sector failure & $\begin{array}{l}\text { Incapacity of the Municipality to regenerate the } \\
\text { territory and to face depopulation by itself }\end{array}$ \\
\hline & $\begin{array}{l}\text { Institutional environment } \\
\text { opportunities }\end{array}$ & Possibility to access EU funding \\
\hline & $\begin{array}{l}\text { Legitimacy, leadership and } \\
\text { additional contribution of actors }\end{array}$ & $\begin{array}{l}\text { Municipality as an institutional safeguard of the } \\
\text { community interest } \\
\text { Leadership of the mayor } \\
\text { Presence of affective entrepreneurs }\end{array}$ \\
\hline & $\begin{array}{l}\text { Preexisting relationships among } \\
\text { actors }\end{array}$ & $\begin{array}{l}\text { Existence of close relationships among the affective } \\
\text { entrepreneurs and the community }\end{array}$ \\
\hline \multirow{5}{*}{$\begin{array}{l}\text { Cross-sector } \\
\text { collaboration in } \\
\text { action }\end{array}$} & Formalized structures & $\begin{array}{l}\text { Combination of for-profit and non-profit } \\
\text { organizations (two limited liability companies, one } \\
\text { joint stock company, one cooperative) }\end{array}$ \\
\hline & Formal and informal processes & Existence of a cross participation system \\
\hline & $\begin{array}{l}\text { Collaborative capacity and } \\
\text { competencies }\end{array}$ & $\begin{array}{l}\text { Involvement of affective entrepreneurs and } \\
\text { community members }\end{array}$ \\
\hline & Leadership & Centrality of the Municipality \\
\hline & Governance & Creation of a community-based network \\
\hline \multirow{4}{*}{ Results } & $\begin{array}{l}\text { Immediate, intermediate and } \\
\text { long-term effects }\end{array}$ & $\begin{array}{l}\text { Immediate effects: creation of new job opportunities, } \\
\text { restoration of abandoned buildings } \\
\text { Intermediate effects: fighting depopulation } \\
\text { Long-term effects: revitalization of the entire } \\
\text { community }\end{array}$ \\
\hline & $\begin{array}{l}\text { Economic, social and } \\
\text { environmental outcomes }\end{array}$ & Positive economic, social and environmental impacts \\
\hline & Public value & $\begin{array}{l}\text { Enhancement of a sense of belonging and possibility } \\
\text { to thrive amid uncertainty }\end{array}$ \\
\hline & $\begin{array}{l}\text { Formal and informal } \\
\text { accountability }\end{array}$ & $\begin{array}{l}\text { Formal procedures } \\
\text { Informal cross-checking interrelationships }\end{array}$ \\
\hline
\end{tabular}

As far as the preconditions is concerned, a great motivation at the basis of the process is the urgency to face the inexorable depopulation process that has been affecting the Municipality of Castel del Giudice in the last decades, and to structure a successful urban regeneration process. Although this aspect could not be considered as a proper public sector failure, since it is also related to a wider demographic phenomenon, it is undeniable that the local government recognized its incapacity to remedy this problem on its own and tried to face it through forms of collaborations with other actors. As stated by the mayor, 'given the failures of previous policies, it was necessary to imagine new paths and to not replicate models so far ineffective', (Interview with Lino Gentile, Mayor of Castel del Giudice-our translation). In this sense, national and supra-national policies played a role, especially in terms of financial stimuli. It is significant that all the initiatives benefited from public grants, namely EU funds. A financial effort has to be acknowledged also on the part of the municipality when it granted citizens' involvement in some companies (e.g., citizens that were interested in becoming a cooperative member of Artemisia could benefit from special municipal funding). Beside this, the municipality was able to engage the availability of some private entrepreneurs who became partners in founding, governing and managing these initiatives. Such private actors have contributed with technical and financial resources but also with their social background. They all run their main businesses far away 
from the area of Castel del Giudice but they still feel they belong to their original community. For this reason, they can be considered as effective entrepreneurs. They share strong territorial identification and cultural values with the other members of the community and this strengthens the bonds of trust and legitimacy. Interpersonal relationships between them and community members preexisted and relapsed into the network. In this sense, the role played by the mayor was (and still is) crucial. He strongly believed in the necessity to "move" towards solutions able to engage different actors and give value to the historical and natural heritage of the territory. His long story as local political leader has assured continuity to the effort to realize initiatives inspired by the values of inclusion and collaboration. He has the leadership and legitimacy to promote this political action. His presence as the representative of the municipality, and in some cases the formal partnership of the municipality itself, can be conceived as a kind of 'institutional guarantee, as it generally happens in small municipalities. The municipality represents the state in the broader sense. In this kind of territory, there are no other institutions apart from the municipality. So, it becomes the guarantor that things have to be done and are done well', (Interview with Lino Gentile, Mayor of Castel del Giudice-our translation).

Moving to the second category of items we considered (i.e., cross-sector collaboration in action), it is noteworthy that the formal structure of the collaboration is here represented by four different organizations: three are profit enterprises (RSA S. Nicola s.r.l., Vello s.p.a, and Melise s.r.l.) with a public-private cross-shareholding, and a cooperative (Artemisia) owned by some community members, which benefited from the technical and financial support of the municipality. It is also noteworthy that, in this latter case, we can talk of a CBE in a stricter sense. However, all these ventures constitute sorts of "institutional boxes" in which and among which collaboration occurs. The choice of the legal model for each venture was the result of a judgment made in respect to the activity they have to carry out and the aims they have to pursue. Moreover, a formalized system of cross participation among these organizations has been created (see Figure 1), also with some members that are engaged as stockholders, officers, or workers in more organizations. These formal structures are also connected with informal relations and processes, which are emphasized also because the operating context is very small. From these connections the whole activity of the network can benefit, making it more adequate to the necessity of the users, some of which are directly involved in the productive processes. It is also to be noted that Vello s.p.a. and Melise s.r.l. signed a service contract for the maintenance of green areas and urban furniture of Hotel Borgotufi, further witnessing interactions within the network. In this setting, in order to guarantee the operational activity of the collaboration, leadership and collaborative capacity, and competencies are vital, as underlined by Bryson, Corby, and Stone [11]. In the case of Castel del Giudice, the affective actors have offered their entrepreneurial experience. The presence of inhabitants as stockholders, officers, and/or employees has positively affected the success of cross-sector collaboration since it is likely to enhance interpersonal understanding, openness to collaboration, and concern for the common good, confirming what Crosby and Bryson [16] believe. Clearly, the above-mentioned institutional guarantee of Municipality of Castel del Giudice, member, and/or supporter of any venture, constitutes the central point of leadership and legitimation of the whole network. We could affirm that the identification of this network might represent one the most interesting findings of the research. Although all the organizations involved are formally autonomous, they are tied by formal and informal links. These interconnections make the network a sort of single experience that can support the effects of each venture's activity. In this sense, we consider it a second level of cross sector-collaboration inspired by a community interest.

As for the results, our analysis indicates the presence of immediate, intermediate, and long-term effects. As immediate and discernible effects directly referable to the collaboration processes, we could consider the creation of new job opportunities and the restoration of abandoned places and buildings. These effects constitute a basis for a further level of results, which cover a longer range of time: the creation of job opportunities is an effective way to fight depopulation and make the area more attractive for new inhabitants. The initiatives promoted in the network activated a kind of virtuous economic circle: other businesses (e.g., a pharmacy and a supermarket) were (re)started and a lead 
to a general increase of the local economy. Moreover, the renovation of the old town contributes to making the life in the area of Castel del Giudice more appealing. In a long-term perspective, we could also assume a positive social impact through this revitalization of the entire community. In addition, some specific units of the network have demonstrated a particular attention on environmental issues with probable positive long-term effects. For example, Melise carries out its activity exclusively with an organic approach, while Vello s.p.a. restored the buildings for "albergo diffuso" Hotel Borgotufi using anti-seismic criteria and only original recycled materials. Finally, an increase in the sense of community and the territorial consciousness are presumable. In this sense, the experience of Castel del Giudice shows the importance of the involvement of diverse actors in order to create public value. As stated by Bryson, Corby, and Stone [11] public value creation would not be possible by a single sector alone; but it becomes reachable 'by using each sector's characteristic strengths while finding ways to minimize, overcome, or compensate for each sector's characteristic weaknesses' (p. 656). Our analysis provides a good example of public value creation as an extension of the public sphere [46] since through the network of Castel del Giudice the local community is experiencing an enhancement of a 'sense of belonging, meaning, purpose, and continuity', and people are enabled 'to thrive and strive amid uncertainty' (p. 43).

In respect to the analysis of accountability processes, we must admit that it is a complex issue, especially in the field of cross-sector collaboration, because of the difficulty to understand to whom and for what exactly different actors should be accountable [11]. However, in the case of Castel del Giudice, two different kinds of accountability mechanisms are recognizable. The first one is related to the legal requirement prescribed for each organization involved in the network. Italian law establishes mandatory tools (e.g., stockholders' meetings and publication of periodical financial statements) to allow stakeholders to scrutinize the behavior of specific actors. The second level of accountability consists of informal crosschecking due to the interrelationships among all the actors involved in the network. The close links that tie all the members of the small community of Castel del Giudice and the system of multiple cross-shareholding on which the network is based constitute a way to exert a constant crosschecking.

\section{Conclusions}

In recent years, there has been an increase in social innovative solutions to cope with public problems. One inspiring idea is to engage the community and create new relationships with public institutions and enterprises, so as to use each sector's characteristic strengths in the creation of public value. In this sense, we have assumed that CBE could be considered as an experience of cross-sector collaboration in order to deal with the dramatic phenomenon of depopulation of marginal areas, and to structure a process of urban regeneration. This study evidenced the reaction of a very small town, Castel del Giudice, which has been affected by serious problems of depopulation and economic depression. The municipality, with the leading role of the mayor, has developed business ventures, with the involvement of different actors and with the aim to revitalize the town and offer to the population new avenues for economic and social development. Results show the presence of innovative forms of collaboration and, particularly, introduce the potentiality of a community-based network as a second-level form of $\mathrm{CBE}$, which can potentiate the effects of each venture's activity to pursue community interests more effectively.

Accordingly to Mehling and Kolleck [51], the results presented should not be read as providing general knowledge about the phenomenon of cross-sector collaborations as such, neither about CBEs in general, but as offering 'theoretically informed patterns identified through conducting interviews and analyzing documents in respect to a unique cross-sector partnership' (p. 20). In this way, the study shows the necessity to conduct a context-sensitive analysis on the specific process of cross-sector collaboration, providing however tentative theoretical concepts that can be used to inform further research and theorization. 
What is clear, as stated also by the mayor, is that if small municipalities do not become laboratories of good and innovative practices, they will have no future'. The experience of Castel del Giudice can represent a way.

Author Contributions: Conceptualization, L.B. and F.P.; Methodology, L.B. and F.P.; Investigation, L.B. and F.P.; Data analysis, L.B. and F.P.; Writing — original draft preparation, L.B. and F.P.; Writing—review and editing, L.B. and F.P. All authors have read and agreed to the published version of the manuscript.

Funding: This research received no external funding.

Conflicts of Interest: The authors declare no conflict of interest.

\section{References}

1. Peck, J.; Theodore, N.; Brenner, N. Neoliberal Urbanism: Models, Moments, Mutations. SAIS Rev. Int. Aff. 2009, 29, 49-66. [CrossRef]

2. Swyngedouw, E.; Moulaert, F.; Rodriguez, A. Neoliberal Urbanization in Europe: Large-Scale Urban Development Projects and the New Urban Policy. Antipode 2002, 34, 542-557. [CrossRef]

3. Bianchi, M.; Vieta, M. Italian Community Co-operatives Responding to Economic Crisis and State Withdrawal-A New Model for Socio-Economic Development. In Proceedings of the UNTFSSE International Conference, Geneva, Switzerland, 25-26 June 2019.

4. Bingham, L.; Nabatchi, T.; O'Leary, R. The New Governance: Practices and Processes for Stakeholder and Citizen Participation in the Work of Government. Public Adm. Rev. 2005, 65, 547-558. [CrossRef]

5. Peredo, A.M.; Chrisman, J.J. Toward a Theory of Community-Based Enterprise. Acad. Manag. Rev. 2006, 31, 309-328. [CrossRef]

6. Handy, F.; Cnaam, R.; Ganesh, S.; Bath, G.; Meijs, L. Jasmine growers of Coastal Karnataka: Grassroots sustainable community-based enterprise in India. Entrep. Reg. Dev. 2011, 23, 405-417. [CrossRef]

7. Mori, P.A.; Sforzi, J. Imprese di comunità-Innovazione istituzionale, partecipazione e sviluppo locale; Il Mulino: Bologna, Italy, 2018.

8. Evans, G.; Shaw, P. The Contribution of Culture to Regeneration in the UK: A Review of Evidence; LondonMet: London, UK, 2004.

9. Bryson, J.M.; Crosby, B.C.; Stone, M.M. The Design and Implementation of Cross-Sector Collaborations: Propositions from the Literature. Public Adm. Rev. 2006, 44-54. [CrossRef]

10. Carlsson, L.; Berkes, F. Co-management: Concepts and methodological implications. J. Environ. Manag. 2005, 75, 65-76. [CrossRef]

11. Bryson, J.M.; Crosby, B.C.; Stone, M.M. Designing and Implementing Cross-Sector Collaborations: Needed and Challenging. Public Adm. Rev. 2015, 75, 647-663. [CrossRef]

12. Dumont, I. Le "Cooperative di Comunità", un'opportunità per le aree marginali. I casi di Succiso e Cerreto Alpi nell'Appennino reggiano. In Ripartire dal territorio. I limiti e le potenzialità di una pianificazione dal basso; Pollice, F., Urso, G., Epifani, F., Eds.; Università del Salento: Lecce, Italy, 2019; pp. 155-166.

13. Bowen, G. Document analysis as a qualitative research method. Qual. Res. J. 2009, 9, 27-40. [CrossRef]

14. Gubrium, F.; Hollstein, J.A. Handbook of Interview Research: Context and Method; Sage: Thousand Oaks, CA, USA, 2002.

15. Brinnkmann, S. Unstructured and semi-structured interviewing. In The Oxford Handbook of Qualitative Research; Leavy, P., Ed.; Oxford University Press: Oxford, UK, 2014; pp. 277-299.

16. Crosby, B.C.; Bryson, J.M. Leadership for the Common Good: Tackling Public Problems in a Shared-Power World, 2nd ed.; Jossey Bass: San Francisco, CA, USA, 2005.

17. Kooiman, J. Governing as Governance; Sage: London, UK, 1993.

18. Cuthill, M.; Fien, J. Building Community Capacity through Citizen Participation in Local Governance. Aust. J. Public Adm. 2005, 64, 63-80. [CrossRef]

19. Kettl, D.F. The Job of Government: Interweaving Public Functions and Private Hands. Public Adm. Rev. 2015, 75, 212-229. [CrossRef]

20. Brereton, M.; Temple, M. The new public service ethos: An ethical environment for governance. Public Adm. 1999, 77, 455-474. [CrossRef] 
21. O'Flynn, J.; Alford, J. Inside and beyond the black box of contracting out: Evidence from local government. In Proceedings of the PAC Annual Conference-Public Administration and Management, Nottingham, UK, 5-7 September 2005.

22. Lawton, A. Ethical Management for the Public Services; Open University Press: London, UK, 1998.

23. Terry, L.D. Administrative Leadership, Neo-Managerialism, and the Public Management Movement. Public Adm. Rev. 1998, 58, 194-200. [CrossRef]

24. Ostrom, E. Crossing the great divide: Coproduction, synergy, and development. World Dev. 1996, 24, 1073-1087. [CrossRef]

25. Brandsen, T.; Honingh, M. Distinguishing Different Types of Coproduction: A Conceptual Analysis Based on the Classical Definitions. Public Admin. Rev. 2016, 76, 427-435. [CrossRef]

26. Pestoff, V. Co-Production and Third Sector Social Services in Europe: Some Crucial Conceptual Issues. In New Public Governance, the Third Sector and Co-Production; Pestoff, V., Brandsen, T., Verschere, B., Eds.; Routledge: New York, NY, USA; London, UK, 2012; pp. 13-34.

27. Borrini-Feyerabend, G.; Farvar, M.T.; Nguinguiri, J.C.; Ndangang, V. Co-Management of Natural Resources: Organizing Negotiation and Learning by Doing; Kasperek Verlag: Heidelberg, Germany, 2007.

28. Schlappa, H. Co-Management in Urban Regeneration: New Perspective on Transferable Collaborative Practice. In New Public Governance, the Third Sector and Co-Production; Pestoff, V., Brandsen, T., Verschere, B., Eds.; Routledge: New York, NY, USA; London, UK, 2012; pp. 227-244.

29. Taylor, M.; Wilson, M.; Purdue, D.; Wilde, P. Changing Neighbourhoods: Lessons from the JFR Neighbourhood Programme; Policy Press: Bristol, UK, 2007.

30. Balloch, S.; Taylor, M. (Eds.) Partnership Working: Policy and Practice; Policy Press: Bristol, UK, 2001.

31. Tallon, A. Urban Regeneration in the UK; Routledge: London, UK; New York, NY, USA, 2010.

32. Ragozino, S. Plymouth Social Enterprise City: l'impresa sociale per la rigenerazione urbana. Urban@it 2016, 1, 1-15.

33. Bartocci, L.; Picciaia, F. The community cooperation as a coproduction experience in public utilities provision-An international perspective. Int. J. Soc. Sci. Hum. Behav. Study 2015, 2, 158-163.

34. European Union. Communication from the Commission to the European Parliament, The Council, The European Economic and Social Committee and The Committee of the Regions; European Commission: Brussels, Belgium, 25 October 2014.

35. Bartocci, L.; Picciaia, F. Le "non profit utilities" tra Stato e mercato: l'esperienza della cooperativa di comunità di Melpignano". Azienda Pubblica 2013, 3, 381-402.

36. Bandini, F.; Medei, R.; Travaglini, C. Territorio e persone come risorse: Le cooperative di comunità. Impresa Sociale 2015, 5, 19-35.

37. Lober, D.J. Explaining the Formation of Business-Environmentalist Collaborations: Collaborative Windows and the Paper Task Force. Policy Sci. 1997, 30, 1-24. [CrossRef]

38. Stone, M.M.; Crosby, B.C.; Bryson, J.M. Adaptive Governance in Collaborations: Designing Propositions from Research and Practice. In Nonprofit Governance: Innovative Perspectives and Approaches; Cornforth, C., Brown, W.A., Eds.; Routledge: London, UK, 2013.

39. Demirag, I.; Khadaroo, I.; Stapleton, P.; Stevenson, C. The Diffusion of Risks in Public Private Partnership Contracts. Account. Audit. Account. J. 2012, 25, 1317-1339. [CrossRef]

40. Sandfort, J.; Moulton, S. Effective Implementation in Practice: Integrated Public Policy and Management; Wiley: San Francisco, CA, USA, 2015.

41. Emerson, K.; Nabatchi, T.; Balogh, S. An Integrative Framework for Collaborative Governance. J. Public Adm. Res. Theory 2011, 22, 1-29. [CrossRef]

42. Lee, H.; Robertson, P.J.; Lewis, L.; Sloane, D.; Galloway-Gilliam, L.; Nomachi, J. Trust in a Cross-Sectorial Interorganizational Network. Nonprofit Volunt. Sect. Q. 2012, 41, 609-631. [CrossRef]

43. Fligstein, N.; McAdam, D. A Theory of Fields; Oxford University Press: New York, NY, USA, 2012.

44. Innes, J.E.; Booher, D.E. Consensus Building and Complex Adaptive Systems: A Framework for Evaluating Collaborative Planning. J. Am. Plan. Assoc. 1999, 65, 412-423. [CrossRef]

45. Bryson, J.; Sancino, A.; Benington, J.; Sørensen, E. Towards a Multi-Actor Theory of Public Value Co-Creation. Public Manag. Rev. 2017, 19, 640-654. [CrossRef]

46. Benington, J. From Private Choice to Public Value. In Public Value: Theory and Practice; Benington, J., Moore, M.H., Eds.; Basingstoke: Palgrave Macmillan, UK, 2011; pp. 31-49. 
47. ISTAT-Istituto Italiano di Statistica. Popolazione Residente Comunale per Sesso Anno di Nascita e Stato Civile; ISTAT: Roma, Italy, 2019. Available online: www.dati.istat.it (accessed on 29 July 2019).

48. Arduino, A. Castel del Giudice; Arti Grafiche S. Giorgio: Isernia, Italy, 1981.

49. Pombeni, P. La montagna e il governo dell'autonomia. In La Montagna Perduta. Come la Pianura ha Condizionato lo Sviluppo Italiano; Cerea, G., Marcantoni, M., Eds.; Franco Angeli: Milano, Italy, 2016; pp. 23-30.

50. Giudici, D. La montagna abbandonata. Altraeconomia 2013, 146, 26-31. Available online: www.altraeconomia. it (accessed on 29 July 2019).

51. Mehling, S.; Kolleck, N. Cross-Sector Collaboration in Higher Education Institutions (HEIs): A Critical Analysis of an Urban Sustainability Development Program. Sustainability 2019, 11, 4982. [CrossRef]

(C) 2019 by the authors. Licensee MDPI, Basel, Switzerland. This article is an open access article distributed under the terms and conditions of the Creative Commons Attribution (CC BY) license (http://creativecommons.org/licenses/by/4.0/). 